(C) [2006] IEEE. Reprinted, with permission, from [Youguang Guo1, Jianguo Zhu, Jiaxin Chen1 and Jianxun Jin, Performance Analysis of a PM Claw Pole SMC Motor with Brushless DC Control Scheme, Power Electronics and Motion Control Conference, 2006. IPEMC 2006. CES/IEEE 5th International (Volume:2 ) 14-16 Aug. 2006]. This material is posted here with permission of the IEEE. Such permission of the IEEE does not in any way imply IEEE endorsement of any of the University of Technology, Sydney's products or services. Internal or personal use of this material is permitted. However, permission to reprint/republish this material for advertising or promotional purposes or for creating new collective works for resale or redistribution must be obtained from the IEEE by writing to pubspermissions@ieee.org. By choosing to view this document, you agree to all provisions of the copyright laws protecting it 


\title{
Performance Analysis of a PM Claw Pole SMC Motor with Brushless DC Control Scheme
}

\author{
Youguang Guo ${ }^{1}$, Jianguo Zhu ${ }^{1}$, Jiaxin Chen ${ }^{1,2}$, and Jianxun $\mathrm{Jin}^{3}$ \\ ${ }^{1}$ Faculty of Engineering, University of Technology, Sydney, P.O. Box 123, Broadway, NSW 2007, Australia \\ ${ }^{2}$ College of Electromechanical Engineering, Donghua University, Shanghai 200051, China \\ ${ }^{3}$ School of Automation Engineering, U. of Electronic Sci. \& Tech. of China, Chengdu, Sichuan 610054, China \\ youguang@eng.uts.edu.au, joe@eng.uts.edu.au, chjiaxin@dhu.edu.cn, jxjin@uestc.edu.cn
}

\begin{abstract}
Thanks to its unique properties, such as isotropic magnetic and thermal properties and low eddy current loss, the soft magnetic composite (SMC) material is suitable for application in electrical machines, especially those with complex structures and three-dimensional (3D) magnetic fluxes. This paper presents the performance analysis of a three-stack permanent magnet (PM) claw pole motor with an SMC stator core. 3D finite element magnetic analysis and improved formulations are applied to accurately compute the motor parameters, such as the back electromotive force, incremental inductance, cogging torque, and core loss. An equivalent electrical circuit is derived to predict the motor's steady-state performance under a brushless DC control scheme. Because of the large winding inductance of this type of motors, the control of the output torque and speed can be difficult. To verify the motor controllability, a Matlab/Simulink-based simulation model is compiled to simulate the motor dynamic and steady-state performances. Experiments are conducted on the motor prototype, validating the theoretical computations and analyses.
\end{abstract}

Keywords-soft magnetic composite; claw pole motor; brushless DC control; finite element magnetic field analysis; performance simulation.

\section{INTRODUCTION}

Compared to the laminated steels commonly used in electrical machines, the soft magnetic composite (SMC) material possesses a number of advantages, such as isotropic magnetic and thermal properties, low eddy current loss and relatively low total core loss at medium and higher frequencies, net-shape fabrication process with smooth surface and good finish (without need of any further machining), and prospect of very low cost mass production [1]. Therefore, SMC materials have a great potential for electrical machine applications, especially for those with complex topologies and three-dimensional (3D) magnetic fluxes, such as claw pole and transverse flux motors [2].

Due to its powdered nature, SMC is naturally magnetically isotropic, and this creates key design benefits [3]. The magnetic circuits can now be designed with 3D flux paths, and different radical topologies can be exploited to achieve high motor performances, for the reason that the magnetic field does not have to be restricted in the two-dimensional (2D) plane of laminated steels.

To investigate the application potential of SMC, a three-stack permanent magnet (PM) claw pole motor with an SMC stator core has been developed by taking advantage of the unique properties of the material, as shown in Fig. 1 [4]. In this motor, the fluxes generated by the rotor PMs and the stator windings are 3D. For example, the flux produced by the PMs passes the air gap and flows into the stator claw poles via both the face and the side surfaces.

The three phases of the motor are stacked axially with an angular shift of $120^{\circ}$ electrical from each other. Each stator phase has a single coil (not shown in the figure for clarity) around an SMC core, which is molded in two halves. The outer rotor comprises a tube of mild steel with an array of magnets for each phase mounted on the inner surface. Mild steel is used for the rotor because the flux density in the yoke is almost constant.

The major dimensions include: $94 \mathrm{~mm}$ for the outside diameter, $93 \mathrm{~mm}$ for the active axial length, $1.0 \mathrm{~mm}$ for the main air gap, and $40.5 \mathrm{~mm}$ for the average diameter of the airgap, etc. The motor is designed to operate under a brushless DC control scheme, delivering a torque of 2.65 $\mathrm{Nm}$ at $1800 \mathrm{rpm}$.

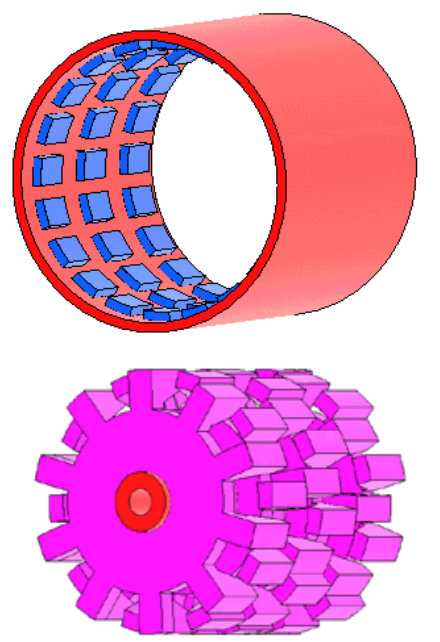

Figure 1. Magnetically relevant parts of the claw pole SMC motor 
Due to the complicated structure, 3D numerical field analysis is required for accurate computation of the motor parameters. In this paper, the $3 \mathrm{D}$ magnetic field finite element analysis (FEA) is performed to calculate the key parameters, such as the winding flux, back electromotive force (emf), inductance and core losses. To predict the motor characteristics, an equivalent electrical circuit is derived under the optimal brushless DC control condition, i.e. the back emf is in phase with the stator current.

Generally, the claw pole machine has a large winding inductance, which may cause difficulty in the control of the output torque and speed. To verify the controllability of the motor, especially at high speed operation, a Matlab/Simulink-based model is complied to simulate the dynamic and steady-state performances. The experimental results on the motor prototype validate the theoretical analyses.

\section{PARAMETER CALCULATION BY 3D FEA}

\section{A. 3D Magnetic Field FEA}

By considering the detailed structure and dimensions of the motor and the non-linearity of ferromagnetic materials, the magnetic field FEA can accurately determine the magnetic field distribution and hence the parameters. Due to the almost magnetic independence and structural symmetry between stacks, only one pole region of one stack is needed for FEA, as illustrated in Fig. 2. On the two radial boundary surfaces, the magnetic scalar potentials obey the half-periodical conditions as

$$
\varphi_{m}(r, \Delta \theta / 2, z)=-\varphi_{m}(r,-\Delta \theta / 2,-z)
$$

where $\Delta \theta=18^{\circ}$ is the angle of one pole pitch.

Fig. 3 illustrates the no-load magnetic flux density vectors produced by the rotor PMs. It can be seen that the major path of the PM flux is along one of the PMs - the main air gap - half of the SMC claw pole stator core disk - the stator yoke - another half of SMC claw pole stator core disk - main air gap - another PM and then - the mild steel rotor yoke to form a closed loop. The magnetic field in the armature is really complex and SMC is an ideal candidate as the core material.

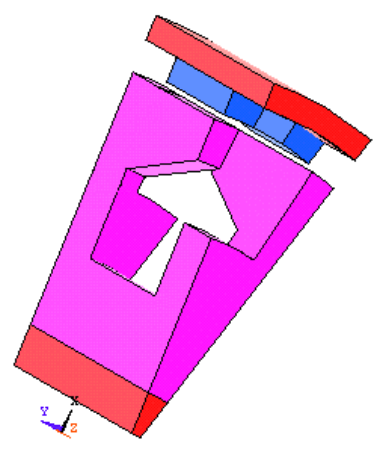

Figure 2. Region for magnetic field FEA

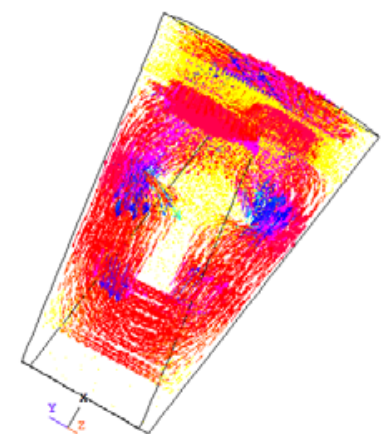

Figure 3. Plots of magnetic flux density vectors at no-load

\section{B. Back emf}

The PM flux, defined as the flux linking a stator phase winding produced by the rotor PMs, can be obtained from the no-load magnetic field distribution (Fig. 3). The flux waveform is calculated by rotating the rotor magnets for one pole pitch in 12 steps. As plotted in Fig. 4, this flux waveform is almost perfectly sinusoidal versus the rotor position.

When the rotor rotates, the PM flux varies and an emf is induced in the stator winding. The emf frequency depends on the rotor speed, while its waveform is determined by the profile of the flux versus the rotor position. The emf constant is $0.2594 \mathrm{Vs} / \mathrm{rad}$, by

$$
K_{E}=\frac{p}{2} N_{1} \frac{\phi_{1}}{\sqrt{2}}
$$

where $p=20$ is the number of poles, $N_{1}=75$ is the number of turns of a phase winding, and $\phi_{1}$ the magnitude of the sinusoidal flux waveform.

\section{Winding Inductances}

The behavior of an electrical circuit is governed by the incremental inductance rather than the secant inductance [5]. In this paper, the phase winding incremental inductance of the claw pole motor is calculated by a modified incremental energy method [6], which includes the following steps: (1) For a given rotor position $\theta$, conduct a non-linear field analysis considering the saturation due to the PMs to find out the operating point of the motor, and save the incremental permeability in each element; (2) Set the remanence of PMs to zero, and conduct a linear field analysis with the saved permeabilities under a perturbed stator current excitation, $\Delta i$; (3) Find out the co-energy; and (4) Calculate the self incremental inductance by

$$
L_{11}(\theta)=\frac{2 W_{c}(\Delta i, \theta)}{(\Delta i)^{2}}
$$

The mutual inductance between phase windings can be considered as zero due to the independent magnetic circuit of each stack. Fig. 5 shows the computed self incremental inductance $\left(L_{i n c}\right)$ of one phase winding at different rotor positions. For comparison, the computed secant inductance $\left(L_{\text {sec }}\right)$ and the measured inductance $\left(L_{\text {mea }}\right)$ by the AC voltage-current method, are also plotted in the figure.

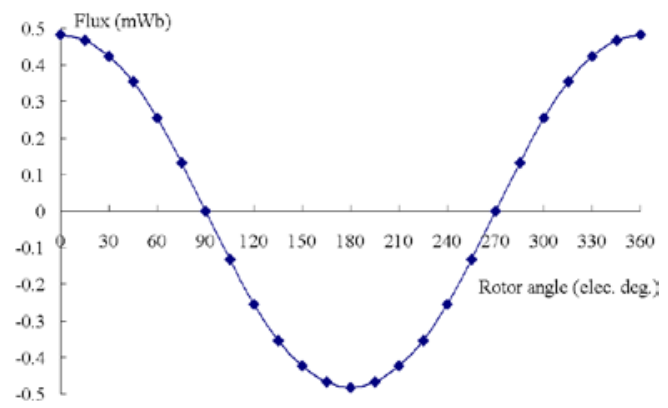

Figure 4. Per turn no-load flux of a phase winding 


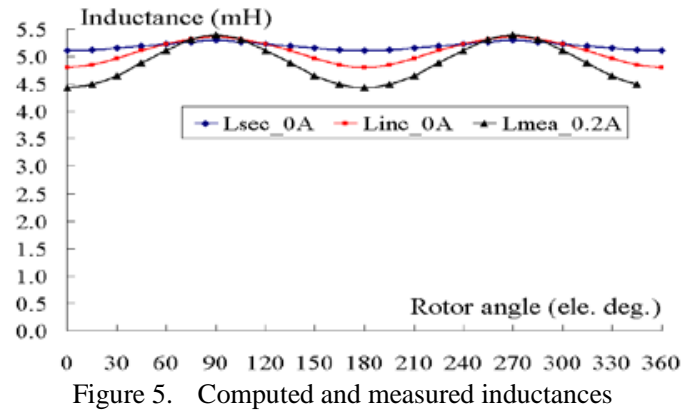

\section{Core Losses}

The core loss is caused not only by alternating but also by rotational magnetic fields, and should be properly considered in the motor design and performance analysis [7]. In this paper, an improved method is applied to predict the core losses in the 3D flux SMC motor [8]. Different formulations are used for core loss prediction with purely alternating, purely circular rotating, and elliptically rotating flux density vectors, respectively. A series of 3D FEAs are conducted to determine the flux density locus in each element when the rotor rotates.

It is found that the core loss increases almost linearly with respect to the rotor speed, due to the dominant hysteresis loss component in SMC. At the rated speed of $1800 \mathrm{rpm}$, the core loss is calculated as $58 \mathrm{~W}$ at no-load, and will increase by about $20 \%$ at the rated load due to the effect of armature current.

\section{SteAdy-STATE PERformanCE CALCUlation by EQUIVALENT ELECTRIC CIRCUIT}

When running in synchronous mode, the motor's steady-state performance can be predicted by the equivalent circuit model as shown in Fig. 6, where $E_{1}$ is the induced stator emf, $R_{1}$ the stator winding resistance, $\omega_{1}$ the angular frequency, and $L_{1}$ the synchronous inductance of the phase winding. The motor is assumed to operate in the optimum brushless DC mode, i.e. $I_{1}$ in phase with $E_{1}$, so that the electromagnetic power and torque can be obtained by

$$
\begin{aligned}
& P_{e m}=m E_{1} I_{1} \\
& T_{e m}=\frac{P_{e m}}{\omega_{r}}=K_{T} I_{1}
\end{aligned}
$$

where $\omega_{r}$ is the rotor speed in $\mathrm{rad} / \mathrm{s}, K_{T}=m K_{E}$ is the torque constant, and $m=3$ is the number of phases. The rms value of the back emf is determined by $E_{1}=K_{E} \omega_{r}$.

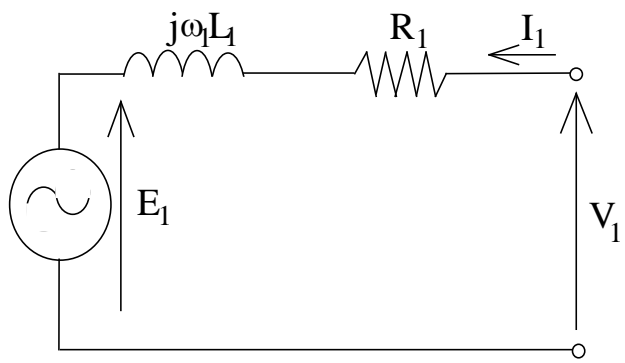

Figure 6. Per-phase equivalent electrical circuit
For a given terminal voltage, $V_{1}$, the relationship between the rotor speed and electromagnetic torque is determined by

$$
\left(\frac{\omega_{r}}{K_{E}}+\frac{R_{1} T_{e m}}{K_{T}}\right)^{2}+\left(\frac{p \omega_{r} L_{1} T_{e m}}{2 K_{T}}\right)^{2}=V_{1}^{2}
$$

The output power, output torque, input power, and efficiency are calculated by

$$
\begin{aligned}
& P_{\text {out }}=P_{\text {em }}-P_{F e}-P_{\text {mec }} \\
& T_{\text {out }}=P_{\text {out }} / \omega_{r} \\
& P_{\text {in }}=P_{\text {em }}+P_{\text {cu }} \\
& P_{\text {cu }}=3 I_{1}^{2} R_{1} \\
& \eta=P_{\text {out }} / P_{\text {in }}
\end{aligned}
$$

where $P_{F e}$ is the core loss, $P_{\text {mec }}$ the mechanical loss including windage and friction, and $P_{c u}$ the copper loss.

\section{PERFORMANCE ANALYSIS BY A}

\section{MATLAB/SiMULINK-BASED SiMULATION MODEL}

The large winding inductance of claw pole motors has effect on the rise rate of the stator current, which may cause difficulties in motor control and limit the motor output toqrue, especially when the motor operates at high speeds. In this paper, the output capacity, such as the maximum steady-state speed that the motor can reach for a given load torque and inverter voltage, is investigated by a Matlab/Simulink-based simulation model. The presented model can also be employed to simulate the dynamic characteristics, such as the curves of speed, current and torque during the start-up or transients when the load or power supply varies.

\section{A. Modeling of Brushless DC Motor with Sinusoidal Waveform Back emf}

For simplification, the phase winding inductance can be considered as a constant, e.g. the average value over a variation cycle. From Fig. 5, the average self-inductance of a phase winding is $L=4.9 \mathrm{mH}$. The mutual inductance between two phase windings is negligible, i.e. $M=0$. The voltage equations of the three phase windings can be written as

$$
\left[\begin{array}{l}
V_{a} \\
V_{b} \\
V_{c}
\end{array}\right]=\left[\begin{array}{ccc}
R_{1} & 0 & 0 \\
0 & R_{1} & 0 \\
0 & 0 & R_{1}
\end{array}\right]\left[\begin{array}{l}
i_{a} \\
i_{b} \\
i_{c}
\end{array}\right]+\left[\begin{array}{ccc}
L & M & M \\
M & L & M \\
M & M & L
\end{array}\right] \frac{d}{d t}\left[\begin{array}{l}
i_{a} \\
i_{b} \\
i_{c}
\end{array}\right]+\left[\begin{array}{c}
E_{a} \\
E_{b} \\
E_{c}
\end{array}\right]
$$

where $V_{a}, V_{b}$, and $V_{c}$ are the voltages of three phase windings, $i_{a}, i_{b}$, and $i_{c}$ the three phase currents, and $E_{a}, E_{b}$, and $E_{c}$ the three phase back emfs.

For the symmetrically distributed three phase windings with star connection, the three phase currents obey

$$
i_{a}+i_{b}+i_{c}=0
$$

The three phase back emfs are: 


$$
\left\{\begin{array}{l}
E_{a}=E_{m} \sin (\omega t) \\
E_{b}=E_{m} \sin (\omega t-120) \\
E_{c}=E_{m} \sin (\omega t-240)
\end{array}\right.
$$

where $E_{m}=\sqrt{2} K_{E} \omega_{r}$ is the magnitude of the sinusoidal back emf, $\omega$ the angular frequency, and $\omega=(p / 2) \omega_{r}$.

The electromagnetic torque is calculated by

$$
T_{e m}=\frac{E_{a} i_{a}+E_{b} i_{b}+E_{c} i_{c}}{\omega_{r}}
$$

The motion equation is

$$
\frac{d \omega_{r}}{d t}=\frac{T_{e m}-T_{L}-\delta_{0} \omega_{r}}{J}
$$

where $T_{L}$ is the load torque, $\delta_{0}$ the friction coefficient, and $J$ the total inertia of the rotating parts.

\section{B. Power Electronic Drive Circuit}

Fig. 7 illustrates the schematic diagram of the typical drive circuit of brushless DC motors, from which one can work out the relationship between the phase voltages and terminal potentials (voltages) as

$$
\left[\begin{array}{c}
V_{a} \\
V_{b} \\
V_{c}
\end{array}\right]=\left[\begin{array}{l}
U_{a}-U_{N} \\
U_{b}-U_{N} \\
U_{c}-U_{N}
\end{array}\right]
$$

where $U_{a}, U_{b}, U_{c}$, and $U_{N}$ are the electrical potentials (voltages) of terminals $a, b, c$ and $N$ (the neutral point), respectively, and $\mathrm{U}_{\mathrm{dc}}$ is the $\mathrm{DC}$ link voltage of the inverter.

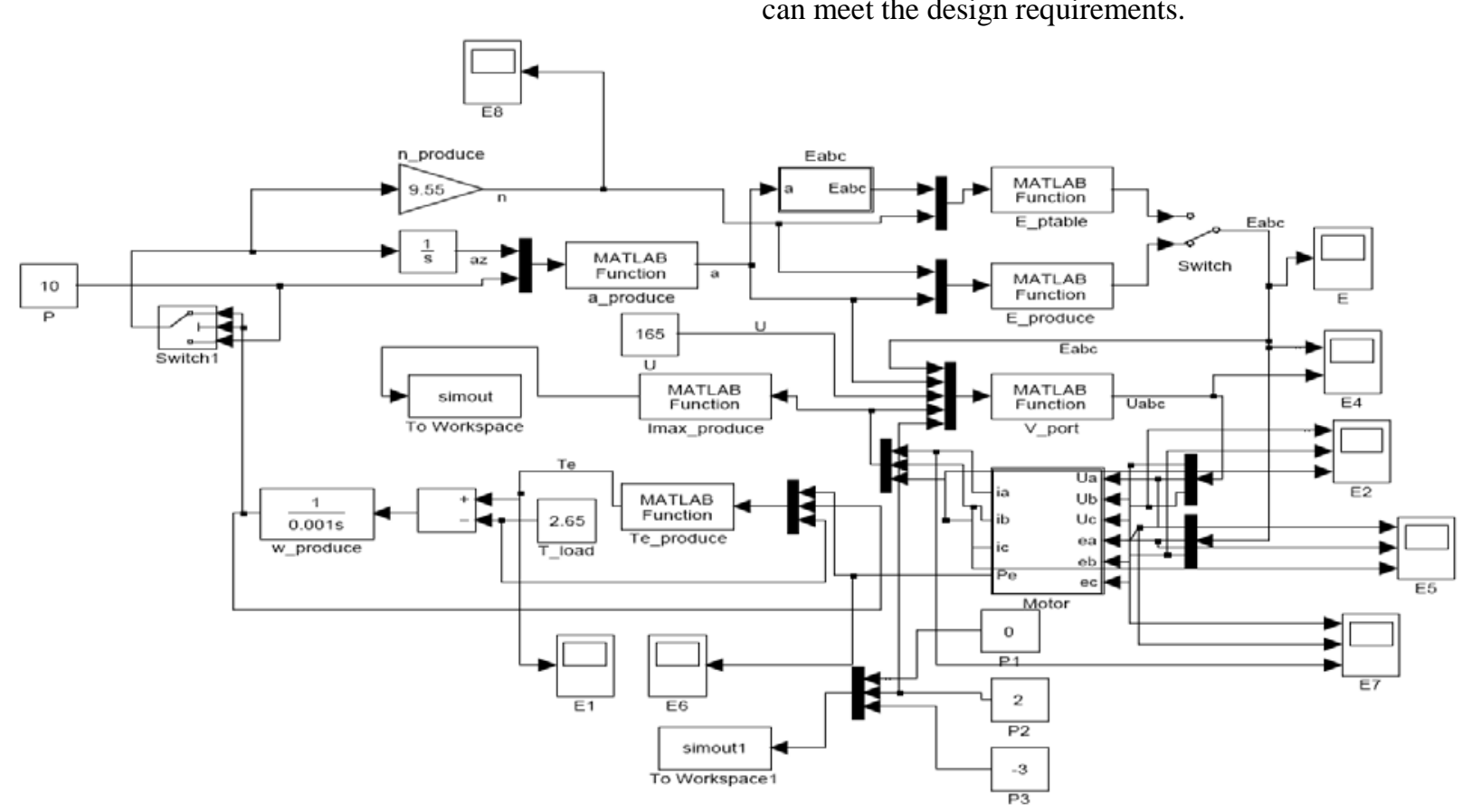

Figure 8. Matlab/Simulink-based simulation model of the brushless DC motor with sinusoidal back emf

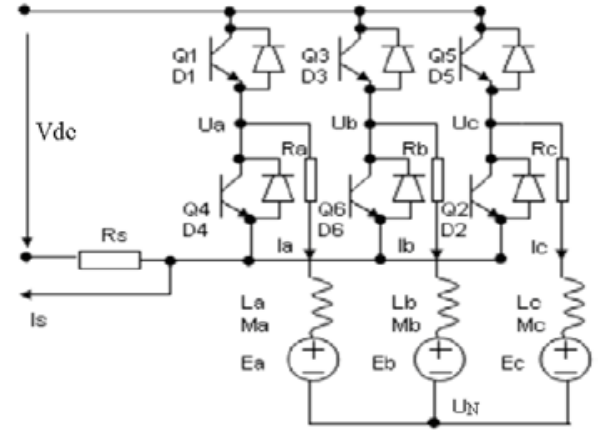

Figure 7. A typical drive circuit for brushless DC motor

Assuming that the hard switching is applied, at the moment when phase $a$ is positively excited and phase $b$ is negatively excited, the following equations can be obtained:

$$
U_{N}= \begin{cases}\frac{\sum_{k=a}^{c}\left(U_{k}-E_{k}\right)}{3} & i_{c} \neq 0 \\ \frac{\sum_{k=a}^{b}\left(U_{k}-E_{k}\right)}{2} & i_{c}=0\end{cases}
$$

\section{Performance Simulation}

According to (12)-(18), a Matlab/Simulink-based simulation model is built as shown in Fig 8. The basic design requirement for the motor drive system is that for an output torque of $2.65 \mathrm{Nm}$, the steady-state speed can reach $1800 \mathrm{rpm}$ when the applied voltage is $\mathrm{V}_{\mathrm{dc}}=165$ VDC. By using the proposed model, the motor drive system is simulated under these conditions and some results are plotted in Figs. 9-11, showing that the motor can meet the design requirements.

Figure 8. Matlab/Simulink-based simulation model of the brushless DC motor with sinusoidal back emf 


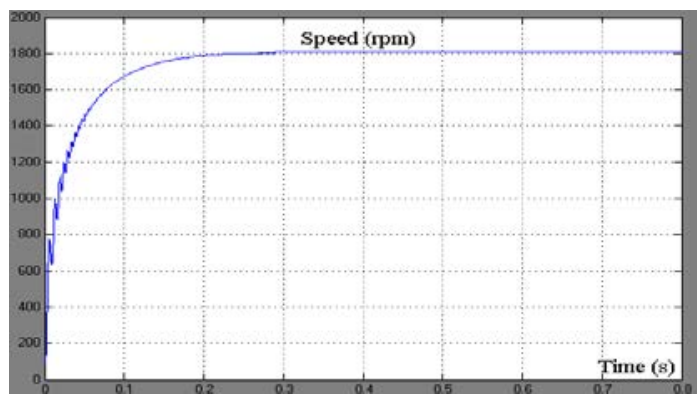

Figure 9. Speed curve during the start-up with a load of $2.65 \mathrm{Nm}$ when the inverter voltage $\mathrm{Vdc}=165 \mathrm{~V}$

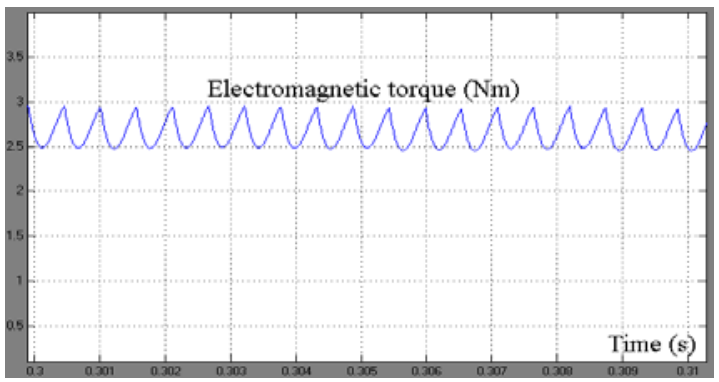

Figure 10. Steady-state electromagnetic torque when Vdc $=165 \mathrm{~V}$

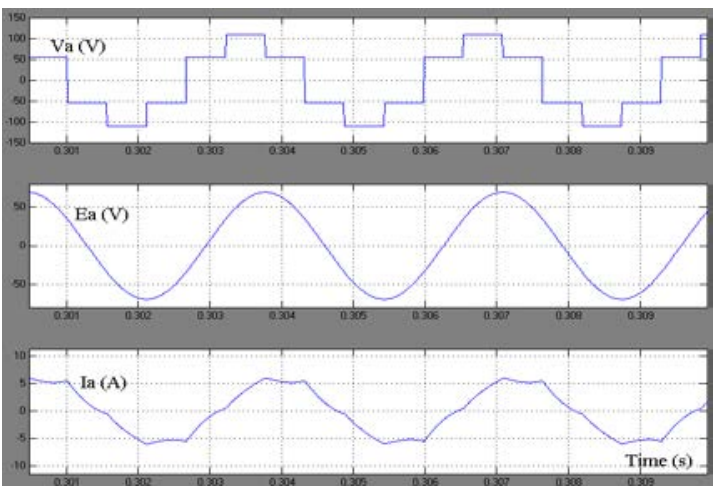

Figure 11. Voltage, back emf and current of a phase winding

\section{EXPERIMENTAL VALIDATION}

The motor prototype has successfully operated with a sensorless brushless DC scheme, delivering a toque of $2.65 \mathrm{Nm}$ at $1800 \mathrm{rpm}$ when the inverter DC link voltage is 165 V. Fig. 12 plots the measured torque/speed curves with different inverter voltages. It can be seen that the theoretical analysis agrees well with the experiments.

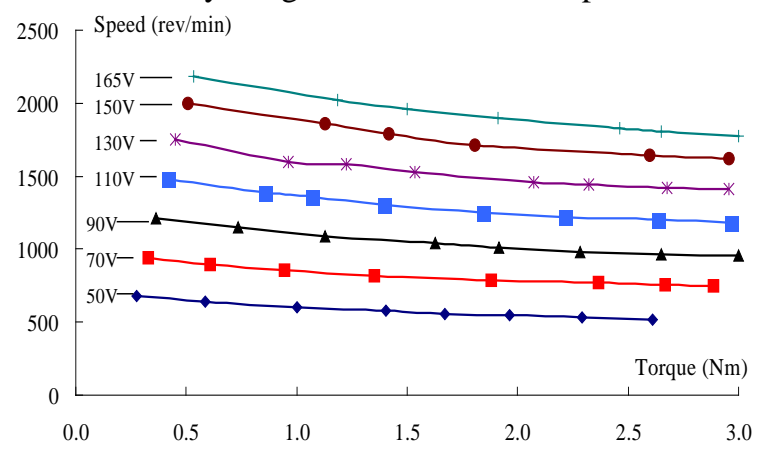

Figure 12. Measured mechanical characteristics

\section{CONCLUSION}

SMC materials have a great application potential in electrical machines, particularly those with complex topologies and 3D fluxes. This paper presents the performance analysis of a three-stack PM claw pole motor with an SMC stator core by an equivalent electrical circuit and a Matlab/Simulink-based simulation model.

For accurate computation of the motor parameters, the 3D finite element magnetic field analysis is conducted. By the numerical analysis, the rotor position dependence of the back emf and inductance has been determined and can be considered in the simulation model for more accurate analysis.

The calculations and simulations have been validated by the experimental results on the claw pole SMC motor prototype.

\section{REFERENCES}

[1] "The latest development in soft magnetic composite technology," SMC Update, Reports of Höganäs AB, Sweden, 1997-2005.

[2] Y. G. Guo, J. G. Zhu, P. A. Watterson, W. Wu, "Comparative study of 3-D flux electrical machines with soft magnetic composite core,” IEEE Trans. on Industry Applications, Vol. 39, No. 6, pp. 1696-1703, Nov. 2003.

[3] A. G. Jack, "Experience with the use of soft magnetic composites in electrical machines," in Proc. Int. Conf. on Electrical Machines, Istanbul, Turkey, Sept. 1998, pp. 1441-1448.

[4] Y. G. Guo, J. G. Zhu, P. A. Watterson, and W. Wu, "Development of a claw pole permanent magnet motor with soft magnetic composite stator," Australian J. Electrical \& Electronic Engineering, Vol. 2, No. 1, pp. 21-30, 2005.

[5] M. Gyimesi and D. Ostergaard, "Inductance computation by incremental finite element analysis,” IEEE Trans. Magn., Vol. 35, pp. 1119-1122, 1999.

[6] Y. G. Guo, J. G. Zhu, H. W. Lu, R. Chandru, S. H. Wang, and J. $\mathrm{X}$. Jin, "Determination of winding inductance in a claw pole permanent magnet motor with soft magnetic composite core,” in Proc. Australasian Univ. Power Eng. Conf., Hobart, Australia, Sept. 2005, pp. 491-496.

[7] Y. G. Guo, J. G. Zhu, J. J. Zhong, and W. Wu, "Core losses in claw pole permanent magnet machines with soft magnetic composite stators,” IEEE Trans. Magn., Vol. 39, No. 5, pp. 31993201, Sept. 2003.

[8] Y. G. Guo, J. G. Zhu, J. J. Zhong, P. A. Watterson, and W. Wu, "An improved method for predicting magnetic power losses in SMC electrical machines,” Int. J. Applied Electromagnetics and Mechanics, Vol. 19, pp. 75-78, 2004. 